\title{
A Solution Procedure for Three-Dimensional Incompressible Navier-Stokes Equation and Its Application
}

Dochan Kwak, James L.C. Chang, and Samuel P. Shanks 


\section{A Solution Procedure for Three-Dimensional Incompressible Navier-Stokes Equation and Its Application}

Dochan Kwak, Ames Research Center, Moffett Field, California James L. C. Chang

Samuel P. Shanks, Rocketdyne Division, Rockwell International, Canoga Park, California

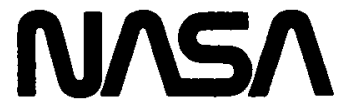

National Aeronautics and

Space Administration

Ames Research Center

Moffett Field, California 94035 


\title{
A SOLUTION PROCEDURE FOR THREE-DMENSIONAL INCOMPRESSIBLE NAVIER-8TOKES EQUATION AND ITS APPLICATION
}

\author{
Dochan Kwak \\ NASA Ames Research Center, Moffett Field, California \\ James L.C. Chang and Samuel P. Shanks \\ Rocketdyne Division, Rockwell International, Canoga Park, California
}

\section{Introduction}

A major difficulty when solving the incompressible flow equations that use primitive variables is caused by the pressure term which is used as a mapping parameter to obtain a divergence-free velocity fleld. One commonly used approach is to solve the Poisson equation for pressure, which is derived from the momentum equations [1]. This approach can be very time consuming. To accelerate the pressurefleld solution and alleviate the drawback associated with the Poisson equation approach, Chorin [2] proposed the use of artiflcial compressibility in solving the continuity equation. A similar method was adopted by Steger and Kutler [3] and Chakravarthy [4] using an implicit approximate-factorization scheme [5]. Based on this procedure, a pseudocompressible method has been developed for solving threedimensional, viscous, incompressible flow problems cast in generalized curvilinear coordinates $[6,7]$. The purpose of the present paper is to show salient features of the pseudocompressible approach, which is primarily designed for obtaining steady-state solutions effliently.

\section{Description of the Method}

In the present formulation, the three-dimensional, incompressible Navier-Stokes equations are modifled to form the following set of governing equations written in dimensionless form :

$$
\begin{gathered}
\frac{1}{\beta} \frac{\partial p}{\partial t}+\frac{\partial u_{i}}{\partial x_{i}}=0 \\
\frac{\partial u_{i}}{\partial t}+\frac{\partial u_{i} u_{j}}{\partial x_{j}}=-\frac{\partial p}{\partial x_{i}}+\frac{\partial \tau_{i j}}{\partial x_{j}}
\end{gathered}
$$

Here, $\mathrm{t}$ is time; $x_{i}$ are the Cartesian coordinates; $u_{i}$ are corresponding velocity components; $\mathrm{p}$ is the pressure; and $\tau_{i j}$ is the viscous stress tensor. The parameter $1 / \beta$ is the pseudocompressibility. As the solution converges to a steady state, the pseudocompressibility effect approaches zero, yielding the incompressible form of the equations. In the present study, the approximate factorization scheme by Beam and Warming [5] is implemented to solve the finite-difference form of the governing equations written in general curvilinear coordinates (see ref. 6 for detail).

In the present formulation, waves of finite speed are introduced. And the system of modifled equations given by equations (1a) and (1b) can be marched in time. The magnitude of the wave speed depends on $\beta$. To recover the incompressible phenomena, 
the physics requires that the pressure wave propagates much faster than the spreading of vorticity. From this, the following criterion for the lower bound on $\beta$ is obtained [7]:

$$
\beta>\left[1+4\left(x_{r e f} / x_{\delta}\right)^{2}\left(x_{L} / x_{r e f}\right) / R e\right]^{2}-1
$$

where $x_{\text {ref }}$ is the reference length, and $x_{\delta}$ and $x_{L}$ are the characteristic lengths that the vorticity and the pressure waves have to propagate during a given timespan.

The upper bound on $\beta$ depends upon the particular numerical algorithm chosen. In the present study, higher-order cross-differencing terms are added to obtain the approximately factored form of the governing equations. These added terms contaminate the momentum equations as well as the continuity equation, and therefore must be kept smaller than the original terms everywhere in the computational domain. This requirement leads to the following criterion for the upper bound of $\beta$ :

$$
\beta \Delta \tau<O(1)
$$

where $\Delta \tau$ is the time-step used in the integration scheme.

\section{Computed Results}

Numerical experiments were performed to illustrate the present procedure. To represent an internal flow, the flow through a channel at $\operatorname{Re}=1,000$ was chosen. The coordinate system and velocity vectors for a converged solution are shown in figures $1 \mathrm{a}$ and $1 \mathrm{~b}$. To change the ratio of the time scales required for the pressure waves and the vorticity to map the entire flow field, the channel length, $L$, is varied form 20 to 40 . The recommended values of $\beta$ for these cases using $\Delta \tau=0.1$ are:

$$
0.75<\beta_{L=20}<10, \quad 1.19<\beta_{L=30}<10, \quad 1.69<\beta_{L=40}<10
$$

In table 1 , the number of iterations for one roundtrip by the pressure wave (denoted by $N_{1}$ ) is tabulated for various values of $\beta$ which include values outside the recommended range. In figure 2, root-mean-square (RMS) values of (div $u)$ are plotted to check the accuracy of the converged solutions. When the value of $\beta$ is out of the range specified, the accuracy of the solution deteriorates.

To represent an external flow, the flow past a circular cylinder at a $R e=40$ was chosen. To obtain the near-fleld solution only, the distance traveled by the waves and the spreading of the vorticity can be approximately the same in magnitude. In the present case, this leads to the range for $\beta$ using $\Delta \tau=0.1$ to be $0.1<\beta<10$. This indicates that the magnitude of $\beta$ is less restrictive for external flows. In figures $3 a$ and $3 b$, the stream-function contours and the pressure coefficient on the surface are shown for a steady-state solution. This solution agrees very well with that of Mehta who used a stream function and vorticity formulation in two dimensions (private communication, U. B. Mehta, 1983). In flgure 4, in which the history of the pressure drag is shown for an impulsively started circular cylinder at $R e=40$, four different values of $\beta$ were compared with the time-accurate solution of Mehta. In all cases, the 
values of $\beta$ are selected within the suggested range above, and the solutions converge rapidly.

To test internal flows further, an annular duct with a $180^{\circ}$ bend is chosen. This conflguration is similar to the turnaround duct of the hot-gas manifold in the Space Shuttle main engine (SSME). In figures $5 \mathrm{a}$ and $5 \mathrm{~b}$, the geometry and a laminar solution at $R e=1,000$ are shown, which reveals the formation of a large separated bubble after the $180^{\circ}$ bend. For this geometry, the streamwise length normalized by the duct width is 20 . The test problems presented here were treated using a $51 \times 17 \times 21$ mesh for half-duct formulation and the computing time required was $1.1 \times 10^{-4} \mathrm{sec}$ per mesh point per time-step on the Cray X-MP computer at NASA Ames Research Center.

\section{Concluding Remarks}

This paper presents salient features of the computational procedure developed for a three-dimensional, incompressible, Navier-Stokes code. This procedure has been applied to various geometrically complex flows, including a major application in analyzing the flow field in the SSME power head. The present algorithm has been shown to be very robust and accurate if the selection of $\beta$ is made according to the guidelines presented here.

\section{References}

1. Harlow, F. H.; and Welch, J. E.: Numerical Calculation of Time-Dependent Viscous Ineompressible Flow with Free Surface, Phys. of Fluids, vol. 8, no. 12, Dec. 1965, pp. 2182-2189.

2. Chorin, A. J.: A Numerical Method for Solving Incompressible Viscous Flow Problems, J. Comput. Phys., vol. 2, 1967, pp. 12-26.

3. Steger, J. L.; and Kutler, P.: Implicit Finite-Difference Procedures for the Computation of Vortex Wakes, AlAA J., vol. 15, no. 4, Apr. 1977, pp. 581-580.

4. Chakravarthy, S. R.: Numerical Simulation of Laminar Incompressible Flow within Liquid Filled Shells, Report ARBRL-CR-00491, U.S. Army Ballistics Research Laboratory, Aberdeen Proving Ground, Md., Nov. 1982.

5. Beam, R. M; and Warming, R. F.: An Implicit Finite-Difference Algorithm for Hyperbolic Systems in Conservation-Law Form, J. Comput. Phys., vol. 22, Sept. 1976, pp. 87-110.

6. Kwak, D.; Chang, J. L. C.; Shanks, S. P.; and Chakravarthy, S.: An Incompressible Navier-Stokes Flow Solver in Three-Dimensional Curvilinear Coordinate Systems Using Primitive Variables, AIAA Paper 84-253, Reno, Nev., 1984.

7. Chang, J. L. C.; and Kwak, D.: On the Method of Pseudo Compressibility for Numerically Solving Incompressible Flows, ALAA Paper 84-252, Reno, Nev., 1984. 
Tebe 1: Number of iterctions required for on roundtrip by presen bermen in end out-flom boundery of D chasond: Ro $=1000$ and $\Delta t=0.1$

\begin{tabular}{|c|c|c|c|c|c|c|c|}
\hline \multicolumn{2}{|c|}{$\beta$} & 0.1 & 1 & 2 & 5 & 10 & 50 \\
\hline \multirow{3}{*}{$N_{1}$} & $L=20$ & 4180 & 500 & 347 & 190 & 133 & 50 \\
\cline { 2 - 8 } & $L=30$ & 6290 & 849 & 520 & 294 & 190 & 80 \\
\cline { 2 - 8 } & $L=40$ & 8391 & 1132 & 693 & 392 & 268 & 115 \\
\hline
\end{tabular}

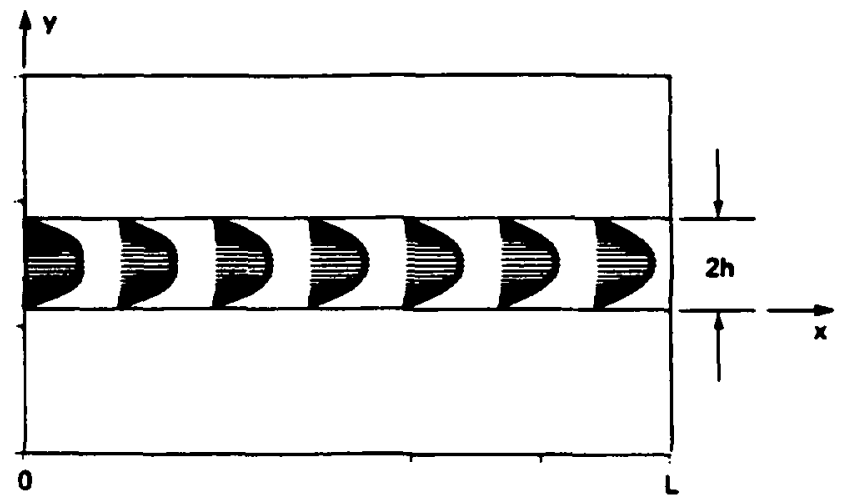

(a) Velocity vector

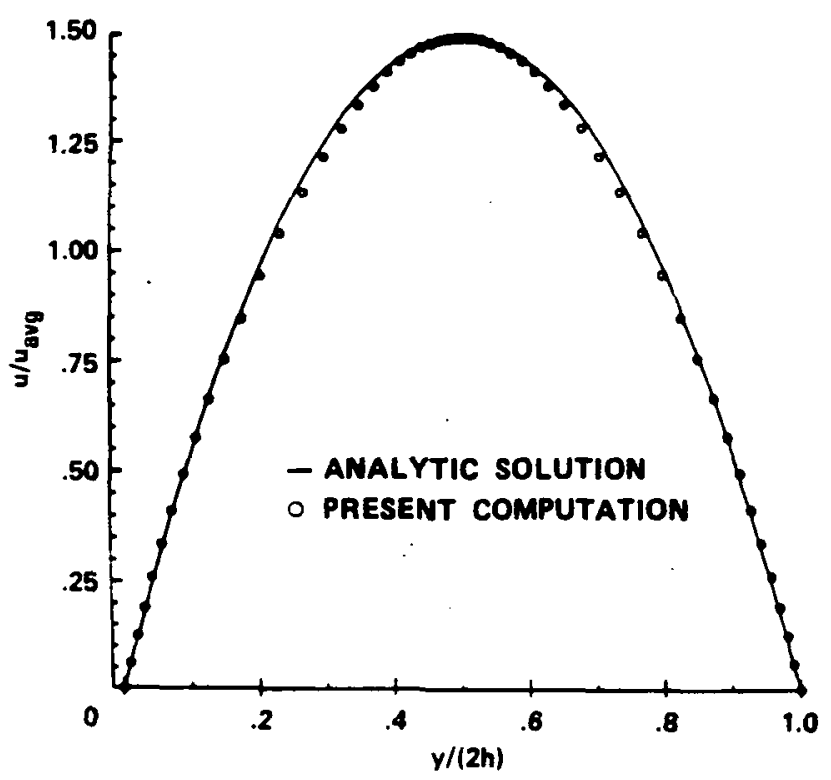

(b) Fully developed velocity profile

Figure 1.- Developing laminar channel flow at $\operatorname{Re}=1,000$ ( $\operatorname{Re}$ based on channel width and average velocity).
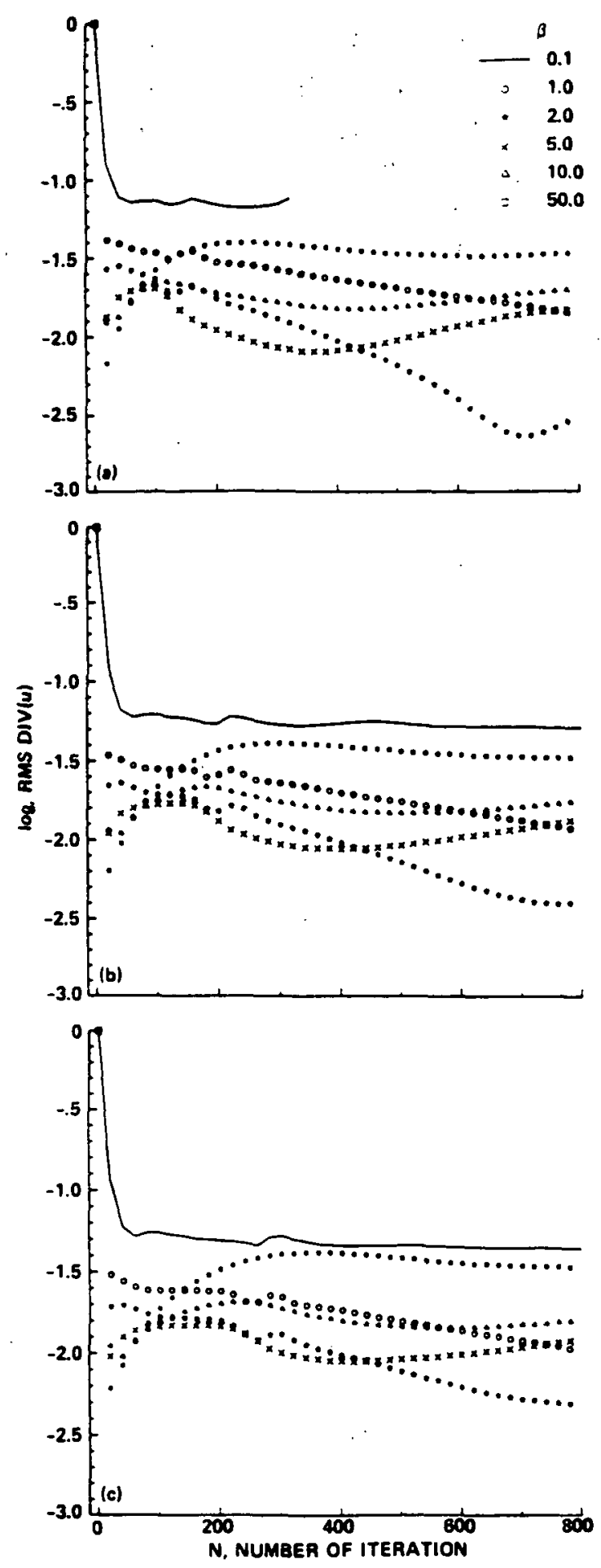

(a) $\mathrm{L}=20$

(b) $\mathrm{L}=30$

(c) $\mathrm{L}=30$

Figure 2.- RMS (divu) history of channel flow at $\operatorname{Re}=1,000$ and $\Delta r=0.1$. 


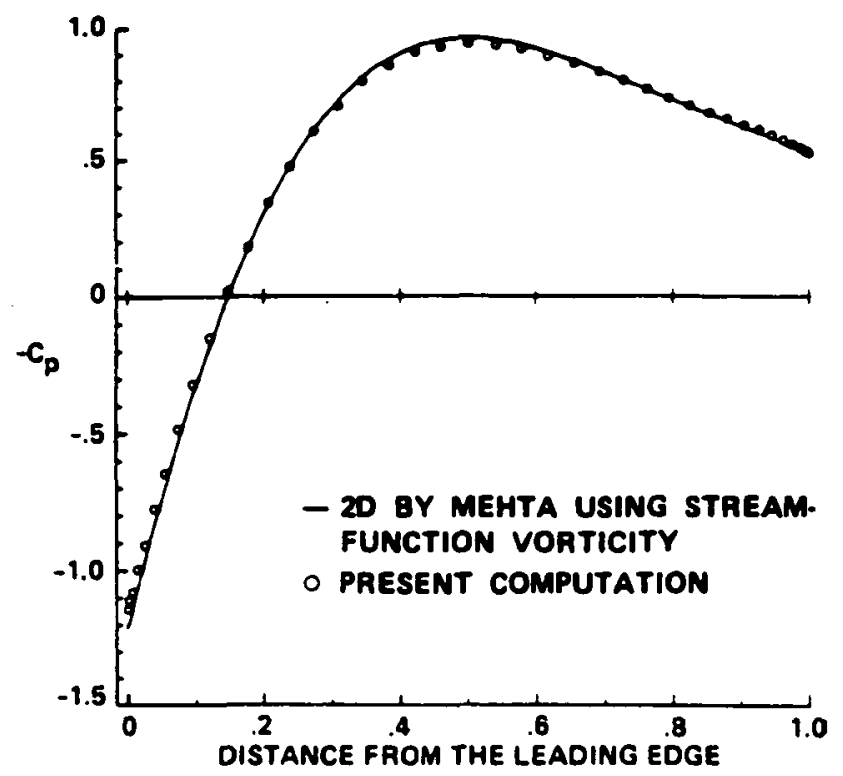

(a) Pressure coefficient on the surface

$\odot$

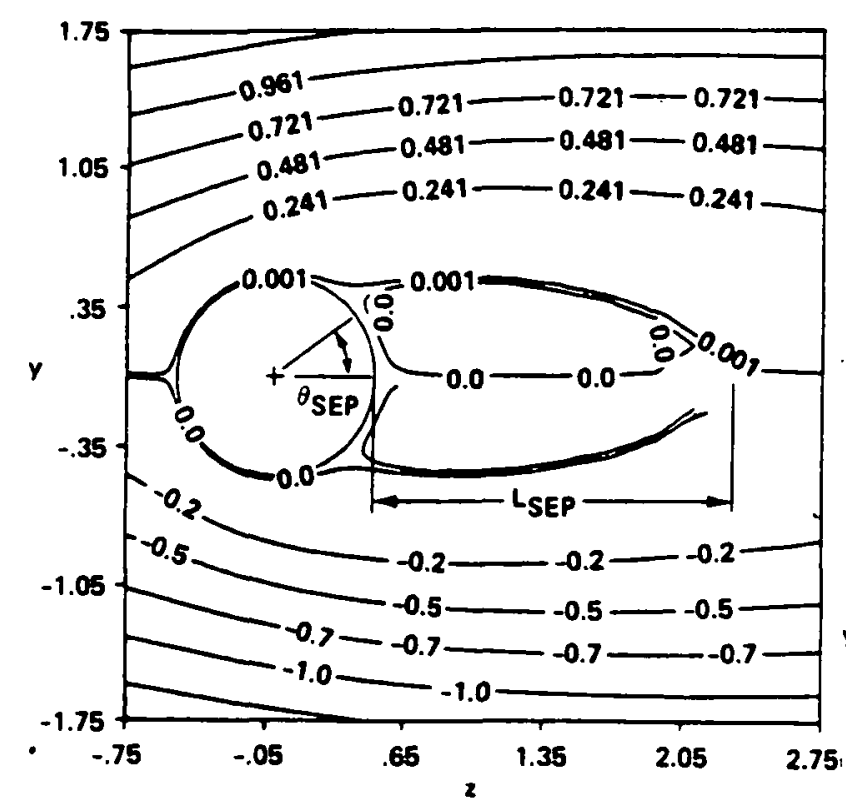

(b) Stream-function contours

Figure 3.- Steady-state solution for flow over a circular cylinder at $\operatorname{Re}=40$.

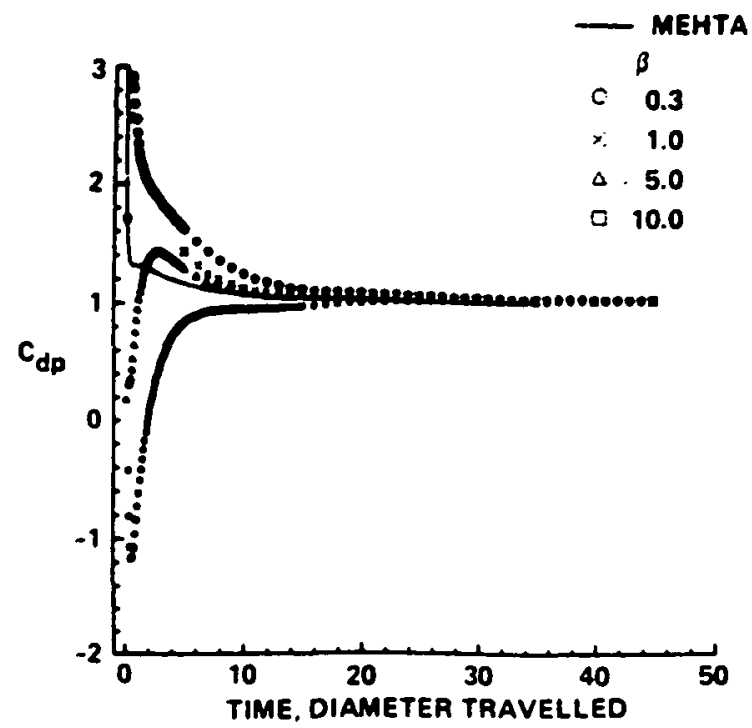

Figure 4.- Pressure drag history for flow over a circular cylinder at $\operatorname{Re}=40$.

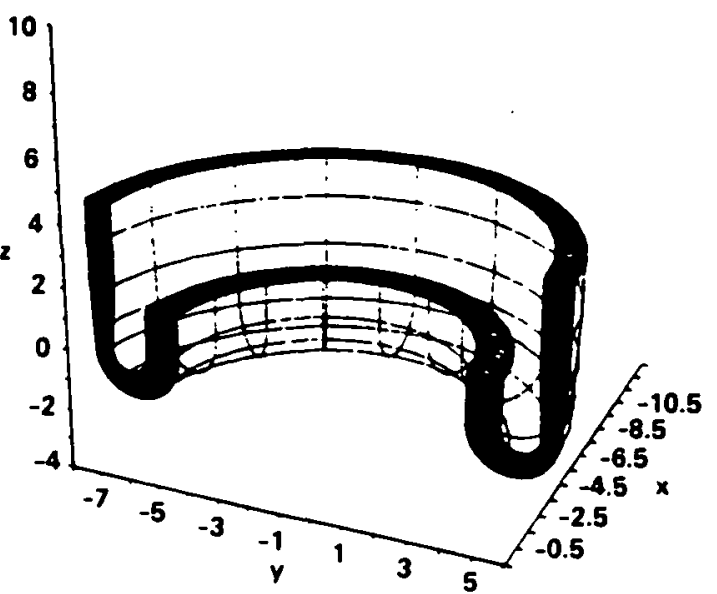

(a) Three-dimensional grid.

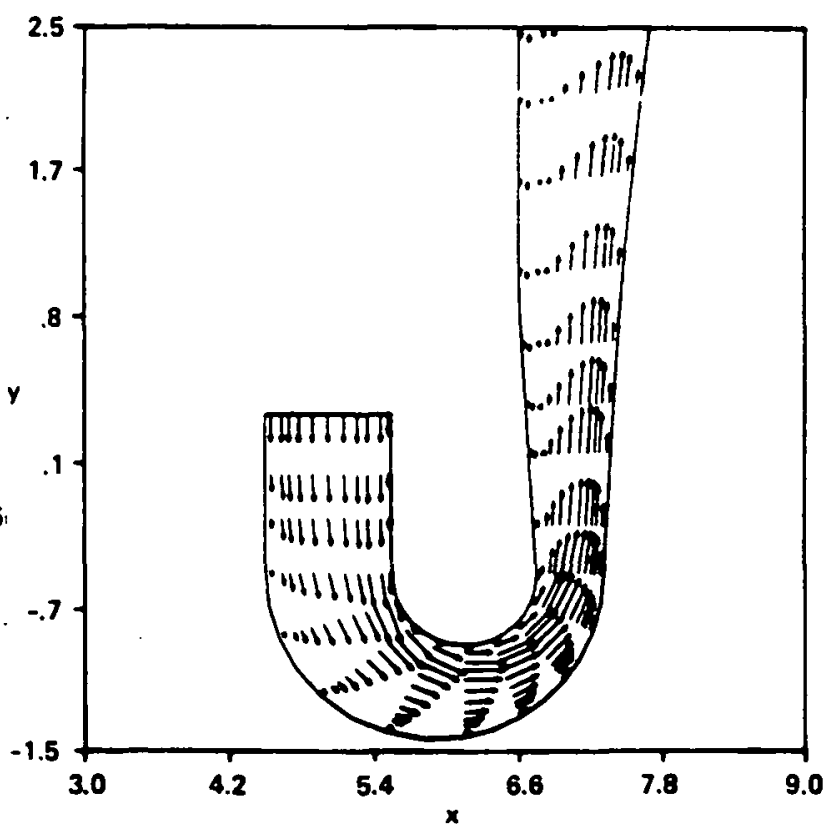

(b) Typical flow pattern with separation.

Figure 5.- Flow through a tumaround duct. 


\begin{tabular}{|c|c|}
\hline $\begin{array}{l}\text { 1. Report No. } \\
\text { NASA TM-85978 }\end{array}$ & 3. Recipient's Catalog No. \\
\hline \multirow{2}{*}{$\begin{array}{l}\text { 4. Title and Subtitle } \\
\text { A SOLUTION PROCEDURE FOR THREE-DIMENSIONAL } \\
\text { INCOMPRESSIBLE NAVIER-STOKES EQUATION AND } \\
\text { ITS APPLICATION }\end{array}$} & $\begin{array}{l}\text { 5. Report Date } \\
\text { June } 1984\end{array}$ \\
\hline & 6. Performing Organization Code \\
\hline \multirow{2}{*}{$\begin{array}{l}\text { 7. Author(s) Dochan Kwak (Ames Research Center), and } \\
\text { James L. C. Chang and Samuel P. Shanks (Rocketdyne } \\
\text { Div., Rockwe1l International, Canoga Park, Calif.) }\end{array}$} & $\begin{array}{l}\text { 8. Performing Organization Report No. } \\
\text { A-9801 }\end{array}$ \\
\hline & 10. Work Unit No. \\
\hline \multirow{3}{*}{$\begin{array}{l}\text { 9. Performing Organization Name and Address } \\
\text { Ames Research Center } \\
\text { Moffett Field, CA } 94035\end{array}$} & $\mathrm{~T}-6458$ \\
\hline & 11. Contract or Grant No. \\
\hline & 13. Type of Report and Period Covered \\
\hline \multirow{2}{*}{$\begin{array}{l}\text { 12. Sponsoring Agency Name and Address } \\
\text { National Aeronautics and Space Administration } \\
\text { Washington, DC } 20546\end{array}$} & Technical Memorandum \\
\hline & $\begin{array}{l}\text { 14. Sponsoring Agency Code } \\
505-31-01\end{array}$ \\
\hline \multicolumn{2}{|l|}{$\begin{array}{l}\text { 15. Supplementary Notes } \\
\text { Point of contact: }\end{array}$} \\
\hline
\end{tabular}

16. Abstract

An implicit, finite-difference procedure is presented for numerically solving viscous incompressible flows. For convenience of applying the present method to three-dimensional problems, primitive variables, namely the pressure and velocities, are used. One of the major difficulties in solving incompressible flows that use primitive variables is caused by the pressure field solution method which is used as a mapping procedure to obtain a divergence-free velocity field. The present method is designed to accelerate the pressure-field solution procedure. This is achieved by the method of pseudocompressibility in which the time derivative pressure term is introduced into the mass conservation equation. The pressure wave propagation and the spreading of the viscous effect is investigated using simple test problems. The present study clarifies physical and numerical characteristics of the pseudo-compressible approach in simulating incompressible flows. Computed results for external and internal flows are presented to verify the present procedure. The present algorithm has been shown to be very robust and accurate if the selection of the pseudo-compressibility parameter, $\beta$, has been made according to the guidelines given in the paper.

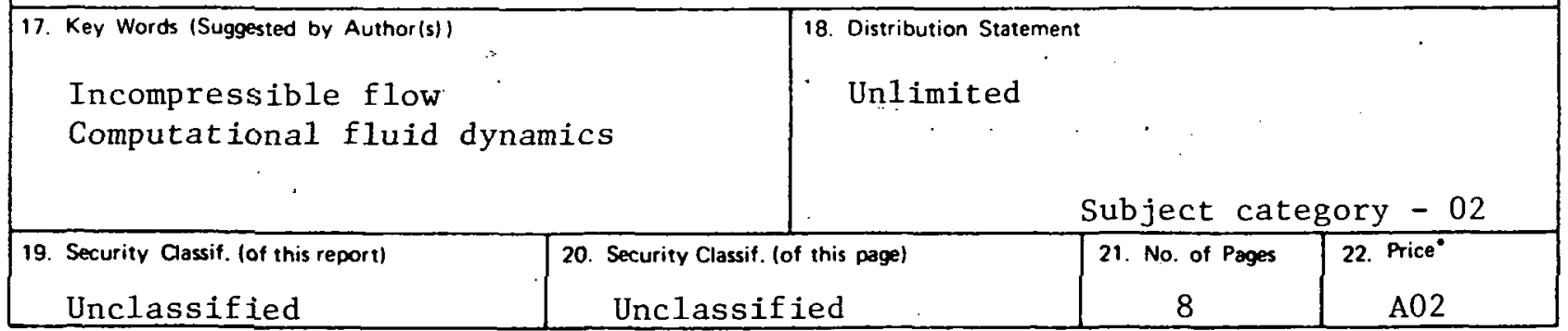

